\title{
De Pais para Filhos: Modos Intencionais de Transmitir Valores
}

\author{
Melina de Carvalho Pereira* \\ Maria Isabel Pedrosa* \\ Universidade Federal de Pernambuco, Recife, PE, Brasil
}

\begin{abstract}
RESUMO
Investigaram-se estratégias utilizadas por pais para transmitir valores aos filhos. Assistir a um filme infantil e simular sua recontação à criança foi o procedimento usado para introduzir nessa temática dez pais/mães, com filho de 6 a 9 anos. Eles participaram de entrevista semiestruturada cujas respostas foram analisadas qualitativamente, revelando diferentes estratégias intencionais para transmitir valores: instruir ativamente o filho; aproveitar notória motivação da criança e lhe agregar valor; e ensinar pela experiência (ou privação dela) proporcionada ao filho. A recontação revelou-se um procedimento adequado de pesquisa, pois os entrevistados realçaram ou minimizaram trechos do enredo para transmitir valores aos filhos ou comentaram que assim o fariam. Destaca-se o potencial de se explorar a temática sob o foco dos estudos intergeracionais.
\end{abstract}

Palavras-chave: valores; família; relações pais-filhos; estratégias parentais.

\section{ABSTRACT \\ From Parents to Children: Intentional Manners of Transmiting Values}

Strategies by parents were investigated in transmitting values onto their children. Seeing a children's movie and simulating retelling to the child was used to introduce ten parents with children aging 6-9. They participated in a semi-structured interview whose answers were qualitatively analyzed, revealing different intentional strategies conveying values: actively instruct their child; take advantage of the child's motivation adding value to it; and teach by experience (or its withdrawal) provided to the child. The retelling proved to be a suitable procedure for research as the respondents highlighted or minimized parts of the plot to transmit values or commented they would do so. It is noteworthy the potential to explore the issue from the standpoint of intergenerational studies.

Keywords: values; family; parent-child relationships; parenting strategies.

Os pais são os principais responsáveis por ensinar a criança regras e valores necessários à sua socialização, incentivando-a e promovendo meios eficazes para que ela aprenda e se desenvolva. Os modos como os pais orientam o comportamento de seus filhos são chamados de práticas educativas parentais. Nas últimas décadas vários estudos têm sido realizados sobre esse tema buscando-se relacionar variáveis específicas a práticas educativas dos pais, algumas vezes apenas da mãe. São exemplos de estudos recentes: Alvarenga e Piccinini (2007), que investigaram a relação do temperamento infantil, da responsividade materna e das práticas educativas maternas, com problemas de externalização e competência social de crianças; Alvarenga e Piccinini (2009), que buscaram relacionar práticas de orientação, controle assertivo e envolvimento parental positivo à competência social, e práticas coercitivas e permissivas aos problemas de externalização; Carmo e Alvarenga (2012), que compararam o uso de práticas coercitivas em mães de diferen- 
tes níveis socioeconômicos e indicaram associação entre mães de nível socioeconômico baixo e maior frequência de punição física; Sampaio e Vieira (2010), que estudaram o gênero dos filhos e a ordem de nascimento, revelando que essas variáveis interferem no modo como os pais os orientam; Minetto, Crepaldi, Bigras e Moreira (2012), que investigaram o nível de estresse parental e as práticas educativas utilizadas por pais de crianças com desenvolvimento típico bem como desenvolvimento atípico (deficiência intelectual e síndrome de Down entre outros.

A influência dos pais nos primeiros anos de vida da criança é inquestionável. Entretanto, permanece ainda pouco explorado na literatura como eles se apropriam da cultura infantil e como agem com o intuito de transmitir valores morais. Um dos recursos usados pelos pais na transmissão de valores é a mídia cinematográfica, mas, em um estudo de revisão, Corsaro (2011) chama a atenção que existem lacunas envolvendo a escuta e avaliações de pais/mães sobre recursos midiáticos como filmes, desenhos animados, etc.

A criação de enredos cinematográficos para instigar um público espectador requer, certamente, uma apropriação de significações da realidade deste mesmo público. Um segmento específico da mídia - nas últimas décadas, reconhecidos como filmes 'de família' ou 'para todas as idades' por não se restringir apenas ao público mais novo (Ramos, 2009) - explora fortemente conteúdos morais compartilhados socialmente. No entanto, ao se destinarem mais especificamente à infância, os enredos de filmes infantis procuram ter um caráter instrutivo e a sociedade cria a expectativa, de fato, de que esse recurso tenha repercussões positivas na formação das crianças. Ao mesmo tempo, os enredos estimulam, de modo sutil, transformações socioculturais que se delineiam em uma nova geração de pais.

O presente estudo se propõe a investigar estratégias utilizadas por pais/mães para transmitir valores a seus filhos usando como recurso um filme de família. Pergunta-se sobre as significações atribuídas por pais circunscritas à expectativa social de que são eles responsáveis primeiramente pela transmissão de valores morais. Fazendo uso dos recursos midiáticos disponíveis, é possível compreender mais fielmente a infância na perspectiva dos pais sobre esta fase de desenvolvimento, na contemporaneidade. Claramente com o estudo, exploram-se também os atores sociais "filhos"; no entanto, estes, sob o olhar de seus pais.

Entende-se que valores morais fazem parte de um sistema simbólico compartilhado, socialmente valorizado em termos de estilo de vida, julgamentos e ações para convivência social. Gouveia, Fonsêca, Milfont e Fischer (2011, p. 298), apoiando-se num trabalho de Kluckhohn de 1951, afirmam que "Um valor é uma concepção, explícita ou implícita, própria de um indivíduo ou característica de um grupo, acerca do que é desejável, o que influencia a seleção dos modos, meios e fins de ações acessíveis". Os valores servem então para orientar condutas em meio a várias possibilidades e selecionar modos para atingir determinado fim.

Compreende-se que as relações interpessoais na família e os valores morais que as permeiam estão em permanente construção por meio de compartilhamentos e negociações em sociedade, variando de acordo com o cenário social. Torna-se importante perceber as recentes modificações na sociedade brasileira, e possivelmente em outras sociedades ocidentais, para compreender, em contexto mais amplo, as relações intergeracionais na família, atualmente.

No Brasil, o Censo de 2010 constatou que, entre 2000 e 2010, a taxa de mortalidade infantil caiu mais de $47 \%$, segundo os dados do Instituto Brasileiro de Geografia e Estatística [IBGE] (2012). Nos mesmos 10 anos, a taxa de fecundidade no país saiu de um valor médio de 2,38 filhos por mulher para 1,90. Infere-se que, com a diminuição da mortalidade infantil, a saúde da criança melhorou em qualidade; com a redução da taxa de natalidade, a mulher (ou o casal) pôde intensificar a atenção diferenciada aos filhos. Essas mudanças no meio familiar sugerem a possibilidade de se olhar a criança de maneira mais individualizada (Ariès, 2006).

Juntamente com as modificações no tamanho e dinâmica da família, ocorreram mudanças no sentido de um modelo mais informal ou mais democrático de relações intrafamiliares, tal como discute Goldani (1993). A autoridade de pai/mãe passa a não ser mais exercida de forma inquestionável ou autoritária. Diante dessas contínuas transformações, pode-se afirmar que na atualidade o 'valor de referência' está mais centrado no individual, em detrimento do familismo ou holismo, conforme defende Singly (2007). A família vem sendo então incorporada neste discurso atribuin- 
do-lhe a função de ajudar cada um a se constituir como pessoa autônoma (Goldani, 1993). O projeto individual passa a se sobrepor ao interesse do grupo, mas isto não significa que o grupo deixe de existir; no entanto, é preciso ajustá-lo. Esta constante mudança de valores tem repercussões em conflitos intergeracionais, testemunhas das rápidas transformações, com reflexos para as relações entre pais e filhos.

Em um trabalho intergeracional, Gheorghiu et al. (2008) confirmaram nas narrativas de classe média a tendência à dissolução da educação autoritária em três gerações: na avaliação dos pais, a educação dada costuma ser mais branda que a recebida. Por transmissão intergeracional, entende-se "a travessia de uma geração à seguinte de legados, rituais e tradições, a qual pode ser consciente ou inconsciente" (Lisboa; FéresCarneiro \& Jablonski, 2007, p. 2). Cada família tem sua forma particular de transmitir valores e costumes.
Sabe-se, entretanto, que a tentativa de transmissão nem sempre resulta em perpetuação de um costume.

Apesar das mudanças no seio familiar, permanece como função social dos pais guiar filhos no que se refere à moralidade. As relações entre pais e filhos são, então, assimétricas, pois se espera que os adultos protejam e eduquem as crianças para a vida em sociedade.

\section{MÉTODO}

\section{Participantes}

Voluntariaram-se para o estudo sete mães e três pais, cuja média de idade foi 38 anos (30 a 53 anos). Eles eram pais/mães de cinco meninos e cinco meninas com idades variando entre 6 e 9 anos, conforme o quadro abaixo:

Quadro 1. Relação entre idade e parentalidade-filiação dos participantes

\begin{tabular}{|l|c|l|c|}
\hline \multicolumn{2}{|c|}{ ADULTO } & \multicolumn{2}{c|}{ CRIANCA } \\
\hline Nome fictício & Idade & Nome fictício & Idade \\
\hline Andrea & 30 & Alex & 9 \\
\hline Cláudio & 34 & Felipe & 6 \\
\hline Marcela & 35 & Ana & 7 \\
\hline Marta & 30 & Tomás & 8 \\
\hline Paloma & 42 & Luiz & 9 \\
\hline Regina & 33 & Élida & 8 \\
\hline Rinaldo & 53 & Natália & 6 \\
\hline Ronaldo & 32 & Rodrigo & 7 \\
\hline Rosa & 41 & Daniela & 8 \\
\hline Vanessa & 50 & Aline & 7 \\
\hline
\end{tabular}

Como critério desta pesquisa, os entrevistados deveriam obrigatoriamente coabitar com a criança, exigência feita no intuito de buscar progenitores que participassem mais proximamente da educação dos filhos. Nenhuma restrição foi feita em casos de filhos adotados ou de família monoparental ou recasada, incluindo também relações homoafetivas.

A escolha por não incluir dentre os participantes da pesquisa padrastos, madrastas - figuras recorrentes no dia a dia das crianças - foi por se perceber que, assim como avós, tios, padrinhos etc., este(a) novo(a) integrante nem sempre exerce a autoridade de forma ple- na, não assumindo obrigatoriamente o papel conferido socialmente aos pais (Sarti, 1996). Ele(a) pode ser responsável pela criança em determinadas circunstâncias, mas em geral tem sua autoridade reduzida na presença dos progenitores. Além do mais, sua convivência com a criança pode ser temporária, já que a vida conjugal se tornou mais instável (Goldani, 1993; Sarti, 1996), em consonância com a busca pela felicidade pessoal (Petrini, 2005; Singly, 2007). Geralmente, ao se dissolver o casamento, distancia-se também a relação deste(a) adulto(a) com o enteado(a). 
A faixa etária das crianças refere-se a uma fase de vida em que os pais começam a intensificar um diálogo com os filhos com a preocupação de instrui-los moralmente a partir das histórias contadas, por se considerar que a criança compreende a mensagem repassada. A idade dos pais foi aleatória, ou seja, foi decorrente da primeira escolha, a idade dos filhos.

Outras informações sobre os participantes não foram disponibilizadas em forma de quadro, pois isso certamente possibilitaria a asssociação de variáveis, facilitando o reconhecimento dos sujeitos. Com relação à instrução educacional, quatro tinham pósgraduação completa; três, pós-graduação em andamento; um tinha como titulação máxima o curso superior completo e dois estavam cursando o nível superior.

Das famílias dos 10 participantes da pesquisa, seis delas eram compostas por pai, mãe e filho(s). Um casal estava em processo de separação conjugal; uma das mães compunha uma família monoparental, convivendo no mesmo lar ela, a filha e a mãe, portanto, três gerações. Dois participantes adotavam um modelo recasado. Em um desses dois casos, coabitava no novo arranjo uma filha de um relacionamento anterior. $\mathrm{Na}$ outra família recasada, o filho mais velho era filho biológico apenas da mulher, mas o entrevistado não fez distinção entre este e seus dois filhos biológicos durante a entrevista. Uma mãe relatou que sua filha era adotiva.

Embora predominando um modelo nuclear, percebe-se que os participantes da pesquisa são exemplificações de tendências atuais nas relações familiares, havendo número crescente de separações e recasamentos, aumento do número de famílias monoparentais, arranjos com filhos de diferentes uniões (Goldani, 1993; Sarti, 1996, Singly, 2007).

Coerente com a suposição, a partir da observação do cotidiano, de que a maioria dos pais já teria assistido ao filme, apenas uma mãe nunca tinha assistido a Ratatouille.

Os pais foram contatados em uma escola privada na qual estudavam seus filhos; essa escola atendia prioritariamente famílias de classe média da cidade do Recife. Acredita-se ser esta classe a principal envolvida nas mudanças descritas anteriormente e a mais característica dos valores prioritariamente voltados ao individualismo (Fonseca, 2005). Todos os pais das crianças de 6 a 9 anos da instituição foram contatados quando iam levar ou buscar seus filhos na escola. Isso ocorreu após o projeto ter sido aprovado pelo Comitê de Ética em Pesquisa Envolvendo Seres Humanos, da Universidade Federal de Pernambuco (CEP/CCS/ UFPE $)^{1}$. Cerca de 50 pais foram convidados, mas apenas 10 aceitaram o convite, disponibilizando-se a participar do estudo. Eles assinaram o Termo de Consetimento Livro e Esclarecido (exigência da Resolução no 196/96 do Conselho Nacional de Saúde). Acredita-se que o grande número de não aceitação se deveu à dificuldade de tempo, conforme sinalização dos próprios pais, pois era necessária a disponibilidade de no mínimo uma hora para participar do estudo.

\section{Material}

Um filme contemporâneo infantil para ser exibido e instigar o debate com os participantes e um roteiro de entrevista semiestruturado.

Para fins da pesquisa, a escolha do filme tinha como objetivo contemplar efetivamente mudança de valores concernentes a família. Foram então elaborados critérios inspirados em Valente (2011): (1) filmes amplamente divulgados que entraram em cartaz nos cinemas (eliminando-se os lançados apenas em DVDs ou em Blu-ray); (2) filmes com a presença explícita ou implícita de família, sendo esta uma temática relevante, independentemente da configuração familiar; (3) filmes lançados a partir do ano de 2000; (4) não inserção de filmes que abordassem prioritariamente uma cultura muito diferente da que estamos inseridos, por exemplo, a cultura oriental. A escolha de filmes lançados a partir de 2000 justifica-se pela maior probabilidade de que estes retratem as recentes transformações quanto ao modelo e o que é valorado na família contemporânea. Com o conceito de família já se levanta uma grande reflexão, pois é possível questionar quais critérios que definem uma família (Carvalho, 2005).

Dentre um conjunto de 16 longas metragens assistidos, o escolhido foi Rattatoulle (Lewis \& Bird, 2007) por muitos especialistas considerado o melhor filme do ano (Ramos, 2009). Para situar o leitor sobre o enredo do filme, será utilizada uma sinopse disponível em site amplamente divulgado no meio digital ${ }^{2}$ :

Na nova aventura animada RATATOUILLE, um rato chamado Remy sonha em se tornar um grande chef francês, mesmo contra os desejos de sua família e do óbvio problema de ser um rato em uma profissão totalmente inapropriada para roedores. Quando o destino o leva aos esgotos de Paris, Remy se vê na 
situação ideal, bem embaixo do famoso restaurante de seu herói culinário, Auguste Gusteau. Apesar dos aparentes perigos de ser um inadequado - e certamente indesejado - visitante na cozinha de um fino restaurante francês, a paixão de Remy pela arte culinária não demora a colocar em marcha acelerada uma engraçadíssima e eletrizante corrida de ratos que invade o mundo da culinária parisiense. Remy então se sente dividido entre sua vocação e a obrigação de voltar para sempre à sua prévia existência de rato. Ele aprende a verdade sobre amizade, família e entende que sua única opção é a de aceitar quem ele é realmente: um rato que deseja ser chef de cozinha.

Nos filmes infantis, o desfecho do enredo geralmente está relacionado à moral que se deseja transmitir. Em Ratatouille, percebe-se que quando Remy se contrapõe aos interesses do grupo, este se dispõe a ajudá-lo na realização de seus sonhos pessoais, caracterizando a preponderância do respeito à individualidade na família. Parece, então, conveniente utilizar esta mensagem e o conflito que é problematizado pelo filme para a discussão com pais.

A pesquisadora elaborou uma edição do filme com menor tempo de duração (38 minutos), já que ele completo corresponde a 111 minutos; as cenas mais relevantes da película foram preservadas, com a preocupação de que o enredo continuasse compreensível. A redução foi feita com o intuito de viabilizar a participação dos pais na pesquisa. O filme foi exibido com equipamento disponível no local da coleta (DVD; notebook; retroprojetor); a gravação do áudio da entrevista foi possível com o uso de um mp3 ou o aparelho de celular.

\section{Procedimentos de coleta}

Para cada participante da pesquisa, foi exibido o recorte do filme. A entrevistadora esteve disponível para realizar a pesquisa no domicílio do participante ou em outro local da escolha dele, desde que fosse possível manter um ambiente propício para a livre expressão do sujeito, preferencialmente sem a companhia de outras pessoas. Os demais locais foram: o próprio ambiente da escola a partir da qual foram contatados (existia um acordo prévio com a instituição para disponibilizar uma sala adaptada para a pesquisa) ou ainda o ambiente de trabalho dos pais, no horário de intervalo dos funcionários.

Após a apresentação do filme editado, pediu-se para que o(a) participante simulasse uma recontação da história do filme para seu(sua) filho(a), pois se tinha a suposição de que, no momento de recontação, seriam mais evidenciados os valores que se pretendia transmitir. Em seguida, houve um momento de discussão através de uma entrevista semiestruturada, buscando conhecer a opinião deles sobre o enredo e os personagens do filme, uma apreciação geral sobre a mensagem que era passada para as crianças, bem como seu próprio comportamento em família no que diz respeito à educação dos filhos. A entrevista com cada participante foi gravada em áudio com a concordância dos envolvidos. Ao final da entrevista foram questionados alguns dados socioculturais da família, como instrução educacional, costumes de castigos ou de punições, formas de lazer etc., informações que poderiam, se necessário, esclarecer alguma dúvida. As entrevistas tiveram duração média de 34 minutos, e foram realizadas por umas das autoras que é psicóloga e tem experiência em pesquisa, uma vez que essa tarefa exigia a condução de um roteiro semiestruturado. Para esse tipo de roteiro é relevante conhecer bem os objetivos da pesquisa e ter habilidade para discernir a melhor forma de questionamento, por exemplo: ter flexibilidade na ordem das perguntas que compõe o roteiro, ajustando-o com pertinência à apreciação ou comentário feito pelo participante. Outro exemplo seria o uso de incentivos que possam incitar mais informações úteis à análise dos dados, cuidando, entretanto, para que não sejam formuladas de modo invasivo.

\section{Procedimentos de análise}

Segmentos da audiogravação, tanto da recontação quanto das entrevistas, foram recortados, transcritos e analisados qualitativamente, buscando-se discutir as significações que os pais atribuíam ao tema familismo versus individualismo, bem como outros valores morais que eram trazidos concernentes com essa discussão.

Analogamente aos ganhos de investigação com o recurso da videogravação apontados por Carvalho et al. (1996) e Pedrosa e Carvalho (2005), na audiogravação também se permite rever o dado inúmeras vezes a fim de realçar detalhes e compor uma análise mais minuciosa e precisa. Com a gravação de voz é possível perceber pausas, correções, indecisões quanto às palavras a serem usadas, ênfases e entonação na fala, entre outros indícios relevantes para a interpretação dos dados, que foram então caracterizados no momento da transcrição.

As recontações das histórias e as respostas dadas às entrevistas foram transcritas e constituíram o corpus 
da investigação. $\mathrm{O}$ material produzido por cada sujeito era lido várias vezes, com curiosidade: como o pai/a mãe lida com seu(sua) filho(a)? Como avalia os limites e possibilidades de sua própria atuação? Que valores ele(a) busca transmitir e como se utiliza das mídias cinematográficas para essa tarefa? Seguindo Minayo (2012), a ordenação desse material constitui uma etapa organizativa: rascunham-se alguns aspectos que possibilitam adensá-lo para considerar a riqueza dos detalhes e suas relações, examinando-se sua coerência ou divergência, apoiando-se na literatura revisada. Desse modo, busca-se apropriar de sentidos que vão emergindo e sendo organizados de modo a se configurarem como núcleos de sentidos. Isso é feito, entretanto, com flexibilidade, rearranjando-se o material para que se possam escolher aqueles que assegurem a riqueza dos dados e, ao mesmo tempo, permitam sua apreensão global. Essa é uma etapa laboriosa; um "jogo de experimentação", avaliando-se ganhos e perdas para exploração do material empírico, buscando-se homogeneidade, diferenciações e comparações. A esta etapa segue-se a interpretativa, mas vale realçar que esta já foi iniciada nas diversas tentativas de organização do material empírico.

\section{RESULTADOS E DISCUSSÃO}

A recontação do filme e as entrevistas geraram um rico material de análise que será apresentado e discutido em concomitância, buscando-se apreender as significações atribuídas pelo/a pai/mãe ao enrendo de Ratatouille ou significações explícitas e implícitas dos desdobramentos propiciados por ele, no que concerne a conteúdos morais compartilhados socialmente.

\section{0 momento da recontação como estratégia para transmitir valores}

O procedimento proposto para a pesquisa em si já propiciou a observação do uso de estratégias pelos pais no intuito de instruir moralmente seus filhos. Estes, muitas vezes, utilizaram a recontação da história não apenas para fazer uma síntese do enredo, mas, principalmente, para transmitir valores, apontados posteriormente, como importantes para serem repassados aos seus filhos.

Rosa $^{3}$ (41 anos), mãe de Daniela (7 anos), fala explicitamente que aproveitaria o enredo da história para transmitir mensagens a sua filha:
Rosa $^{4}$ - Como é que eu contaria pra Dani? [pausa da entrevistada] $E$ a história de um ratinho $\left[\mathrm{S}^{4}\right]$ que tem um sonho de ser um grande cozinheiro [S]. Que ele consegue distinguir os cheiros, né?! E saber os... e... e... ter um sonho de ser um cozinheiro e achar que pode ser e não ter fronteiras nenhuma. Seria mais ou menos isso que eu contaria. E aí você vai, né, formando, passando as mensagens pra isso... Que assim que é bom você ter perseverança, que você ir atrás do seu sonho, de querer ser o que você quer ser, [S] independente do que você vai passar na vida [S]. Seria mais ou menos isso. Assim.

Embora a soliticação fosse a simulação de uma recontação da história para sua filha, a entrevistada relata explicitamente que, a partir do filme, ela transmite mensagens: "aí você vai, né, formando, passando as mensagens pra isso...". Tal passagem demonstra que o enredo é utilizado intencionalmente pela mãe para instruir moralmente. Cláudio (34 anos), pai de Felipe (6 anos), é um pouco mais sutil na forma de transmissão de valores a partir da recontação da história. Em sua fala, no entanto, indiretamente, parece ser incentivado o valor da perseverança:

Cláudio - Annn é a história de um ratinho... que tem um sonho de ser cozinheiro... e... ele sabe bem das realidades dele, de como ele é, e do mundo ao redor dele. Mas, mesmo assim, ele acredita... num sonho e numa mensagem de que qualquer um pode ser aquilo que quer. [S]. Só basta querer e ir atrás que ele vai conseguir. Se ele quiser mesmo aquilo, ele vai conseguir.

Posteriormente, ao ser questionado sobre o que ele queria que seu filho mais se apropriasse na história desse filme, Cláudio retoma com outras palavras a mensagem que foi trazida por ele de forma sintética na recontação da história.

Cláudio - É a mensagem que eu acho que é a principal, que, que qualquer um, independente da sua classe social, de sua espécie, até é... é capaz de ter aquilo que ele queira ter. De... de... se quiser ser cozinheiro, ele vai ser cozinheiro. O que ele quiser ser ele pode conseguir ser, vai depender da força de vontade, do estímulo, do... [S]. É isso. [P - Certo].

Observa-se que esses dois excertos da fala de Cláudio se referem a um valor que gostaria que seu filho se apropriasse - a perseverança; o primeiro, extraído da sua própria forma de recontar o filme; o segundo, explicitado por ele quando perguntado. Essa coerência evidencia a recontação do enredo de um filme 
como procedimento adequado à apreensão de valores que pais intencionam transmitir para seus filhos.

Já Ronaldo (32 anos), pai de Rodrigo (6 anos), comenta uma estratégia adotada por ele como forma de se assegurar a transmissão de determinados valores para seu filho. Relata ter o costume de aproveitar o enredo da história para ressaltar aspectos que acha importante, pedindo inicialmente a opinião do filho:

Ronaldo - [...] toda vez que eu termino, é característica minha, eu sempre pergunto pra ele: "O que que tu achou? [S] Qual foi a parte legal?" Aí quando ele fala a coisa que ele achou, eu digo: "Tu percebeu que tinha uma parte que fazia assim?" Tipo, [S] "que o pai queria ajudar o filho, ou que o filho queria que o pai entendesse uma coisa?" Aí ele fez "Eita, foi mesmo." "Tu achou legal?" Aí ele faz: "Ah, aquela parte foi legal." Depois, é... outro dia ele acaba contando a história para mim mesmo! [entrevistado fala em tom de espanto].

Pesquisadora - Com a parte que tu, que tu recontasse pra ele...

Ronaldo - Com a parte que eu recontei para ele. [...] Eu estimulo o raciocínio, sabe?

Ronaldo diz achar eficiente sua estratégia, pois avalia que seu filho incorpora da história os aspectos que foram levantados por ele. Ao perguntar o que o filho achou do filme, o entrevistado acredita estar o estimulando a refletir sobre o que viu, formando uma opinião crítica. Fica evidente que ele considera importante a condução do adulto para realçar alguns pontos importantes e interferir na forma como a criança percebe o enredo. Sendo assim, a opinião do filho deve ser construída em consonância com os valores parentais.

\section{Instruindo ativamente a criança}

Em outros momentos da entrevista, Ronaldo deixa claro que é preciso a condução de um adulto para maximizar a compreensão da criança sobre a mensagem que é passada no filme. De acordo com Tomasello (2003), o adulto humano assume um papel mais ativo do que outros primatas na instrução de crianças para aquisição de uma habilidade ou parcela de conhecimento. Essa instrução ativa - estendida também para conteúdos normativos e valorativos compartilhados socialmente - é um poderoso motor de transmissão cultural na medida em que possibilita que este conhecimento ou habilidade seja passado adiante para outros componentes da mesma cultura.
Com o apoio desse aporte teórico, podemos melhor compreender a preocupação de instruir ativamente seu filho nos trechos do filme em que a mensagem é de difícil compreensão para a criança.

\begin{abstract}
Ronaldo - [...] Têm duas coisas que eu acho importante, né. Uma é no finalzinho mesmo, que aí é uma coisa que é pra adulto explicar pra criança, que não t... não fica claro, que é a história do valorizar os momentos dele como criança, porque quando ele ficar maior, ele vai, vão acontecer coisas na vida dele que vai fazer ele ter lembranças boas das coisas que ele tá aproveitando agora.
\end{abstract}

Apesar do uso recorrente da estratégia de instrução ativa pelos pais, isto não significa que a criança apreenda a cultura passivamente, ou apenas quando a instruem. Se assim o fosse, como ressalta Tomasello (2003), não haveria descobertas e inovações na cultura.

Ainda no âmbito da instrução ativa, realçar aspectos considerados relevantes, bem como subtrair da história trechos pouco educativos também foram relatados como modos intencionais de influenciar os pequenos, elegendo o que deveria ser considerado por estes, como no exemplo de Paloma (42 anos), mãe de Luiz (9 anos).

Paloma - [..] Então eu, eu ia contar pelo viés assim, dos ratinhos, né, [...] então eu ia contar, é... A história,... é, chamando a atenção dele para essa, pra esse fato, não é, ocorrido com os ratos. [S].

Pesquisadora - E um pouco... Será que não seria um pouco, até, é... deixar de falar mais dos humanos, né, no filme. Você cortaria um pouco essa parte?

Paloma - É, é. Porque, assim, o lado positivo do filme é a experiência do ratinho, né [S] que, mesmo com as dificuldades ele conseguiu $[\mathrm{S}]$ realizar o sonho dele, né. [S]. E ele nem sabia que tinha talento, um potencial [S], não é? Através do sentido, do olfato, despertou ele para uma profissão, não é [S]. E aí eu iria assim destacar esse ponto, [S] sabe? Porque, é... no filme, a parte que envolve os adultos, os humanos em si, é uma coisa que a gente vivencia diariamente e não traz nada assim de positivo, né? [S].

Pesquisadora - Mas você acha que seria melhor se não tivesse, então, esse trecho dos humanos, no filme? [E -Não...]. Pra não se passar uma mensagem...

Paloma - É. Eu acho que a, a... o trecho dos, dos ratinhos é muito positivo assim, ele, o autor do filme é muito feliz até porque a gente tem o rato como um 
animal nojento, né? [E - É] Tem o rato como um animal nojento, sujo. E aí ele usa o ratinho e você acaba gostando de rato. [risos] [...] Eu assim, se eu fosse mostrar esse filme pro meu filho, ele já viu várias vezes, mas se eu fosse assim buscar nele, é chamar a atenção dele, eu chamaria pra atenção para essa questão dos ratinhos.

Da mesma forma como fizeram outros entrevistados, Paloma também diz se utilizar do recurso do filme para destacar uma lição para seu filho, ainda que este já tenha assistido à película muitas vezes. Na entrevista com a pesquisadora esta mãe não chega a relatar como contaria, mas sim o que ressaltaria e que a história seria um meio utilizado por ela de transmitir valores como a perseverança. Paloma destacou que aspecto da história daria mais importância, chegando até mesmo a sugerir que algumas partes fossem eliminadas, de forma a melhor instruir moralmente as crianças.

\section{Agregando valores à motivação da criança}

Outra estratégia levantada para transmitir valores foi aproveitar a motivação da criança e a partir disto introduzir aspectos que consideram relevantes. Rosa, mãe de Dani, percebendo o interesse da filha em ser surfista profissional, utiliza o argumento de que, para ser boa profissional na área, é preciso alguns requisitos, como saber línguas, nadar, entre outros:

Rosa - [...] ela disse que quando quer ser... que quando crescer, ela quer ser surfista profissional. Certo? Hoje ela tem sete anos. Aí eu faço assim: "Pô, Dani... Surfista profissional! Né? Vamos pensar em outra coisa... Por que surfista?" "Não, mas eu quero ser surfista!' "Não, mas..." Aí você começa a tentar podar aquilo... Porque não é... digamos a profissão... que seja hoje... Mas aí ao mesmo tempo é uma profissão. É só um exemplo assim... [S] É uma profissão que ela quer... [S] Então você vai... "Então beleza... Vamo, então você quer, então tá certo. Mas pra você ser surfista profissional, pra você viajar, você tem que saber línguas, você tem que estudar." Então ela tá fazendo curso de inglês, ela tá fazendo isso, aí tem que aprender a nadar, porque não pode ser surfista se não souber nadar... Então ela faz natação. Entendeu? Assim... Dentro daquilo que ela quer, você começa a botar outras atividades $[\mathrm{S}]$ pra engrandecer ela e não ao mesmo tempo desvirtuar, mas... Tipo assim... Orientar $[\mathrm{S}]$. Você vai... só... jogando aquilo lá pra ela desvirtuar, não só da profissão, mas também da área acadêmica, de estudar, de ser uma boa aluna, de respeitar as pessoas. [S] Eu acho que é a função d, dos pais é essa.
Interessante realçar o momento em que entrevistada diz: "Pô, Dani... Surfista profissional! Né? Vamos pensar em outra coisa... Por que surfista?" Em seguida ela comenta: "Porque não é... digamos a profissão... que seja hoje...". Por este excerto, aparentemente Rosa não avalia como bom sua filha querer seguir tal profissão, provavelmente por não ser valorizada socialmente no momento atual. No entanto, ela demonstra estar tentando ajustar as atividades que considera importante para sua filha, como aulas de natação e inglês, ao desejo de Dani de ser surfista profissional. E acrescenta que esta é uma atribuição dos pais.

Marta (30 anos), mãe de Tomás (8 anos) aproveita os momentos de lazer com a criança para estimular uma reflexão quanto ao conteúdo transmitido por um filme, por exemplo. O lazer novamente se torna uma oportunidade para instruir moralmente.

Marta - É, a gente sempre sai com ele assim, vai à praia, ao cinema, parques, visita a família, né? É... A gente tá assistindo filme sempre puxando alguma coisa dele: "meu filho, você entendeu isso como?"

\section{Ensinando pela experiência}

Fazer com que a criança experiencie outras formas de convivência social, vivendo, por um período, em um país desenvolvido, também se configura como uma estratégia para que ela perceba que a realidade social pode ser diferente e, inclusive, se preocupe com a mudança, não simplesmente se conformando com o que lhe é apresentado. Nesse caso, os pais não obrigatoriamente expressam diretamente o que pensam, mas proporcionam uma experiência, na sua avaliação, necessária e modificadora dos valores para seu filho.

Cláudio - A possibilidade de a gente morar fora daqui a pouco tempo [...] Pra que os meninos possam ver uma realidade um pouquinho melhor. A gente tá cansado mil das políticas ou dos políticos que [S] deixa um pobre tão pobre e fica um rico tão rico... Enfim. Essa diferença social [S] incomoda a gente e a gente não queria que os meninos crescessem nesse, nisso. Sabe?! Ou simplesmente só acompanhando isso, sem querer mudar, sem [S] é... Aí é... Essa preocupação é mais com isso.

$\mathrm{O}$ que se decide por não fazer também pode ser uma estratégia para não incentivar valores indesejáveis. Paloma diz não realizar grandes festas infantis porque avalia como fútil. E diz que age assim para 
que seu filho permaneça sensível às necessidades dos outros:

Paloma - [...] eu nunca fui de... Acho tão bonito, festa de aniversário, mas, lá em casa, nunca fomos de dar aquelas megafestas, ainda que pudéssemos, acredito que não faríamos [S], não é, porque eu acho que também é uma coisa assim... até tem um lado bonito, positivo, é legal porque socializa, mas não deixa de ser fútil. [S]. Tem outras questões também, né, de ele pensar no outro. Porque eu fico sempre falando "mas filho tem criança... Você é um privilegiado, tem crianças que não tem... E não é uma ou duas, são milhares de crianças que ainda agora, ainda hoje não comeram, desde ontem não comeram, não se alimentaram." Então eu começo a fazer, colocar essas situações para ele refletir. [S] Entendeu, pra que ele não fique assim... é... como é que se diz... é... para que ele não se sinta... eи não sei a palavra... superior, digamos assim, né? [S] Ou então tipo, que não se incomode. Não é nem questão de se sentir superior ou inferior, mas eu quero que ele seja sensivel a essas coisas, [S] que ele perceba que há pessoas que são necessitadas, que ele tem, ainda, nós não somos ricos, nem milionarios, mas o que nós temos é o suficiente, entendeu? [S] Então eu quero que ele olhe que tem pessoas que não têm. Eu sempre vou por esse lado, [S], dialogando entendeu?

Com esse excerto, infere-se, claramente, uma intenção de educar a criança, instruindo-a ativamente quanto à evitação de supérfluos. Essa instrução, entretanto, vem acompanhando uma vivência, em que a criança é privada de um "costume" que faz parte de sua microcultura - "megafestas" de aniversários de crianças. Essa privação, acredita-se, deixa-a sensível a uma reflexão que se quer propiciar ao filho, mesmo que ela seja instada por uma explicação ou justificativa. Assemelha-se ao exemplo anterior deste mesmo subtópico, em que se deseja proporciar uma vivência em outra cultura, supostamente divergente da sua, para que a reflexão seja possível, ou seja, convincente.

Nos dizeres de Paloma, uma estratégia inicialmente adotada por seu marido se torna um modo intencional de ambos (pai e ela própria) para mostrar a Luiz que ele precisa ter responsabilidade e fazer algumas atividades. Nesse sentido, os pais exigem uma ação da criança, como, cuidar da cadela, forrar sua cama, para que esta perceba determinado valor.

Paloma - [Meu esposo] já gosta de educá-lo no sentido assim de ele ter uma responsabilidade. Por exemplo: "Luiz, nós temos a cadela, a cadela é sua, então você coloca o, a ração." [S] A gente já começa a atribuir uma responsabilidade para ele, para que ele não... "Ah, tenho o mundo aos meus pés e eles que façam por mim." [S] Não, ele também tem que ter essa noção de que ele também precisa fazer algo $[\mathrm{S}]$ para conquistar alguma coisa. Então, o lixo é ele quem tira. [S] No começo, quando meu esposo começou com isso, eu ficava com pena (risos de $\mathrm{Pa}-$ loma, seguidos do da pesquisadora). Ele forra a cama do jeito dele, guarda os brinquedos. Ele não faz aquilo com aquela perfeição, mas a gente já estimula.

$\mathrm{Na}$ mesma direção, Marta pede para seu filho doar algum de seus brinquedos ao ganhar outro no intuito de que ele não cresça como uma criança egoísta.

\begin{abstract}
Marta - Ações como doar algum brinquedo, a gente sempre faz isso: "Olhe, você ganhou esse brinquedo, você vai doar esse." [S] Você vê que ele é bem humano. [S] Se você conversar como ele, assim ele vai, ele é uma pessoa que tem muita... é... o sentimento assim de fazer caridade. Eu trabalho muito isso nele, porque ele é filho único e filho único tem sempre esse tabu de ser egoísta $[\mathrm{S}]$ e isso ele não é. Ele não é porque eu não aceito isso. [S] Então, a gente vai passando pra ele dessa forma.
\end{abstract}

Assim como outros participantes da pesquisa, a entrevistada Marta ressalta que seu filho tem determinadas características porque ela o instruiu a partir de seus valores. Sendo assim, seu filho, apesar de não ter irmãos, não é egoísta, porque ela o ensinou; esse comentário pareceu querer evidenciar os efeitos da educação na criança.

Claramente, são usadas estratégias a partir de atitudes e atividades cotidianas para instruir moralmente seus filhos, coerente com Sarti (1996) ao afirmar que é nas relações entre pais e filhos que existe um compromisso maior de se instruir moralmente.

\section{CONSIDERAÇÕES FINAIS}

Diferentes estratégias utilizadas intencionalmente pelos pais para transmitir valores aos filhos foram identificadas: algumas se referem à instrução direta, indicando o que a criança deve valorizar, considerar, ou seguir; outras, aproveitam a motivação da criança e lhe agregam valores, como se estes fossem necessários àquela; outras estratégias implicam proporcionar à criança certa experiência, admitindo que esta a tornará susceptível à aprendizagem de certos valores. Embora não questionados diretamente, os entrevistados avaliam suas estratégias de modo eficiente a partir da observação de seus filhos. 
Na literatura pouco ainda se conhece sobre os modos intencionais de transmitir valores aos filhos. O "filme de família", aquele dirigido explicitamente para crianças, mas de interesse também dos adultos, uma vez que, além de servirem de lazer para seus filhos, configuram-se como meio de problematizar aspectos da vida social e cotidiana, são facilmente tomados como mote para ensinamentos diversos, inclusive para a transmissão de valores. $\mathrm{O}$ presente trabalho pôde contribuir com os estudos da área uma vez que evidenciou diversas estratégias utilizadas intencionalmente pelos pais na transmissão de valores aos filhos, a partir de um "filme de família". Além desta evidência, o filme serviu como recurso metodológico para introduzir os pais numa entrevista, circunscrevendo-o na temática de transmissão de valores; realçase, portanto, a contribuição metodológica do trabalho.

Uma terceira contribuição, também metodológica, diz respeito a peculiaridades a serem consideradas na investigação de valores que são transmitidos de pais para filhos. Se esses valores não forem socialmente compartilhados, num dado momento, ou numa específica microcultura, falar sobre eles e admitir a intencionalidade de transmiti-los pode gerar algum desconforto ao entrevistado e, portanto, poderá haver uma tendência a ocultá-los, deixando-os numa zona de não acessibilidade ao investigador. Neste sentido, um procedimento que possa abordar essa temática de modo menos invasivo e com sensibilidade para capturar detalhes relevantes à discussão é um desafio a ser enfrentado. Desse modo, assistir a um filme, simulando, em seguida, a sua recontação para o filho, pareceu um caminho metodológico interessante e eficaz, na medida em que os entrevistados revelaram valores que gostariam de transmitir aos filhos e adentraram na temática da entrevista com aparente tranquilidade. A seleção de qual parte do filme é escolhida ou omitida para a recontação, bem como os realces e minimizações realizadas falam, por si só, de valorizações e de estratégias dos pais. Como foi possível discutir, no caso específico desta investigação, algumas inferências feitas por meio da recontação puderam ser "validadas" pelo que foi revelado na entrevista que se seguiu.

Outras pesquisas, usando o mesmo procedimento, poderão contribuir para futuros estudos com essa e outras temáticas que se afiguram ser de difícil investigação. Entretanto, é preciso se chamar atenção que o tempo gasto com esse procedimento pode ser desestimulador para o pesquisador; ele precisa considerar o tempo gasto com cada participante para assistir ao filme, mesmo que este seja editado para diminuir sua extensão. Como já foi comentado, também existiram evidências de que um grande número de pais deixou de se voluntariar para participar da pesquisa em face do tempo requerido para assistir a um filme e conversar sobre ele. O tempo empregado pelo pesquisador na coleta de seus dados e a falta de adesão de voluntários à pesquisa são grandes limitações do procedimento empregado. É preciso empreender uma análise de custo-benefício no planejamento da investigação antes de se decidir por este procedimento de coleta.

Finalmente, os resultados da presente investigação instigam a continuidade de investigações na área: como repercutem, nos filhos, as estratégias utilizadas por seus pais? Que transformações são implementadas pelos pais, quanto aos valores e modo de transmiti-los, ao avaliarem as repercussões da educação que receberam pelos seus pais? Realça-se, assim, o potencial de se explorar a temática sob o foco de estudos intergeracionais.

\section{REFERÊNCIAS}

Alvarenga, P., \& Piccinini, C. A. (2007). O impacto do temperamento infantil, da responsividade e das práticas educativas maternas nos problemas de externalização e na competência social da criança. Psicologia: Reflexão $e$ Crítica, 20 (2), 314-323.

Alvarenga, P., \& Piccinini, C. A. (2009). Práticas educativas maternas e indicadores do desenvolvimento social no terceiro ano de vida. Psicologia: Reflexão e Crítica, 22(2), 191-199.

Ariès, P. (2006). História Social da Criança e da Família (2a ed., D. Flaksman, Trad.). Rio de Janeiro: LTC. (Trabalho original publicado em 1973)

Carmo, P. H. B., \& Alvarenga P. (2012). Práticas educativas coercitivas de mães de diferentes níveis socioeconômicos. [versão eletrônica] Estudos de Psicologia, 17(2), 191-197.

Carvalho, A. M. A. (2005). Em busca da natureza do vínculo: uma reflexão psicoetológica sobre grupos familiares e redes sociais. In J. C. Petrini, \& V. R. Cavalcanti (Orgs.), Família, sociedade e subjetividades: uma perspectiva multidisciplinar (pp. 183-194). Petrópolis, RJ: Vozes.

Carvalho, A. M. A.; Bergamasco, N. H. P.; Lyra, M. C. D. P.; Pedrosa, M. I. P. C.; Rubiano, M. R. B.; RossettiFerreira, M. C. T.; Oliveira, Z. M. R.; Vasconcellos, V. M. R. (1996). Registro em vídeo na pesquisa em Psicologia: reflexões a partir de relatos de experiência. Psicologia: Teoria e Pesquisa, 12(3), 261-267. 
Corsaro, W. A. (2009). Reprodução interpretativa e cultura de pares. In F. Müller \& A. M. A. Carvalho (Orgs.), Teoria e prática na pesquisa com crianças: diálogos com William Corsaro (pp. 31-50). São Paulo: Cortez.

Corsaro, W. A. (2011). The sociology of childhood. (3rd ed.). California: Pine Forge Press. (Trabalho original publicado em 1997).

Fonseca, C. (2005). Concepções de família e práticas de intervenção: uma contribuição antropológica. Saúde $e$ Sociedade, 14(2), 50-59.

Gheorghiu, M. D., Gruson, P., \& Vari, J. (2008) Trocas intergeracionais e construção de fronteiras nas experiências educativas das classes médias. Educação e Sociedade, 29(103), 377-399.

Goldani, A. M. (1993). As famílias no Brasil contemporâneo e o mito da desestruturação. Cadernos Pagu, 1 67110.

Gouveia, V. V., Fonsêca, P. N., Milfont, T. L., \& Fischer, R. (2011). Valores humanos: contribuições e perspectivas teóricas. In C. V. Torres, \& E. R. Neiva (Orgs.). Psicologia social: principais temas e vertentes (pp. 296313). Porto Alegre: Artmed.

Instituto Brasileiro de Geografia e Estatística. (2012). Censo 2010: escolaridade e rendimento aumentam e cai mortalidade infantil. 2010. Recuperado em 15 de outubro de 2013, de http://censo2010.ibge.gov.br/noti ciascenso view $=$ noticia $\&$ id $=3 \&$ idnoticia $=2125 \&$ busca $=$ $1 \& \mathrm{t}=$ censo-2010-escolaridade-rendimento-aumentamcai-mortalidade-infantil.

Lewis, B. (Produtor), \& Bird, B. (Diretor). (2007). Ratatouille [DVD]. Emeryville, CA: Pixar Animation Studios.

Lisboa, A. V., Feres-Carneiro, T., \& Jablonski, B. (2007) Transmissão intergeracional da cultura: um estudo sobre uma família mineira. Psicologia em estudo, 12(1). Recuperado em 19 de dezembro de 2013, de <http://www. scielo.br/scielo.php?script=sci_arttext\&pid=S1413$73722007000100007 \& \operatorname{lng}=\mathrm{en} \& \mathrm{nrm}=\mathrm{iso}>$.

Minayo, M. C. S. Análise qualitativa: teoria, passos e fidedignidade. Ciência \& Saúde Coletiva, v. 17, n. 3, p. 621626,2012 .
Minetto, M. F., Crepaldi, M. A., Bigras, M., \& Moreira, L. C. (2012). Práticas educativas e estresse parental de pais de crianças... Educar em Revista, Curitiba, Brasil, n. 43, p. 117-132, jan./mar. 2012. Editora UFPR.

Pedrosa, M. I., \& Carvalho, A. M. A. (2005) Análise qualitativa de episódios de interação: uma reflexão sobre procedimentos e formas de uso. Psicologia: Reflexão e Crítica, 18(3), 431-442.

Petrini, J. C. (2005). Mudanças sociais e mudanças familiares. In J. C. Petrini, \& V. R. S. Cavalcanti (Orgs.). Família, sociedade e subjetividades: uma perspectiva multidisciplinar (pp. 29-53). Petrópolis, RJ: Vozes.

Ramos, L. (2009). Os melhores filmes novos: 290 filmes comentados e analisados. São Paulo: Contexto.

Romanelli, G. (1998). O relacionamento entre pais e filhos em família de camadas médias. Paidéia: cadernos de Psicologia e Educação, 8(14/15), 123-136.

Sampaio, I. T. A., \& Vieira, M. L. (2010). A Influência do Gênero e Ordem de Nascimento sobre as Práticas Educativas Parentais. Psicologia: Reflexão e Crítica, 23(2), 198-207.

Sarti, C. (1996). A família como espelho: um estudo sobre a moral dos pobres. Campinas, SP: Autores Associados.

Singly, F. (2007). Sociologia da família contemporânea. (C. E. Peixoto, Trad.). Rio de Janeiro: FGV.

Tomasello, M. (2003) Origens culturais da aquisição do conhecimento humano. São Paulo: Martins Fontes. (Trabalho original publicado em 1999)

Valente, M. B. B. (2011). A produção de paternidade em "Procurando Nemo": performatividade em redes heterogêneas (Dissertação de Mestrado não publicada). Universidade Federal de Pernambuco, Recife.

Recebido em: 12/11/2013

Última Revisão em: $24 / 07 / 2014$ Aceito em: 20/12/2014

\section{Notas:}

1 Aprovado no dia 06 de fevereiro de 2013 (CAAE: 10969713.4 .0000 .5208 / n ${ }^{\circ}$ do parecer: 194.706).

2 Disponível em: http://www.interfilmes.com

3 Todos os nomes apresentados no estudo são fictícios.

4 As interrupções nas falas são apresentadas entre colchetes, indicando-se a fala da outra pessoa. Comentários acrescentados pela pesquisadora, relacionados ao momento da entrevista ou a indícios relevantes para a interpretação da fala do(a) entrevistado(a), encontram-se entre parênteses.

5 Som de incentivo à continuidade da fala do entrevistado, de agora por diante codificado apenas com a lerta $\mathrm{S}$. 